\title{
OS TRAÇOS DAS ARQUITETURAS MODERNAS DE SAÚDE EM SALVADOR
}

\author{
Ana Carolina De Souza Bierrenbach ${ }^{1}$
}

DOI: 10.5752/P.2316-1752.2017v24n34p58

\section{Resumo}

O artigo apresenta de forma sucinta as arquiteturas das instituições de saúde de Salvador durante a primeira metade do século XX, todas consideradas "modernas". Aponta suas características iniciais, indica suas importâncias e assinala as suas situações atuais. Para tanto, aplica um método que consiste fundamentalmente na pesquisa e interpretação de "pistas voluntárias" (que são informações claras e repetidas deixadas de um modo propositado nos documentos) e de rastros involuntários (que são informações mais discretas e dispersas deixadas sem intenções tão nítidas.

Palavras-chave: História. Arquitetura Moderna. Salvador.

\footnotetext{
1. Arquiteta pela FAU-Mackenzie, Historiadora pela FFLCH-USP, mestre pelo PPGAU-UFBA, doutora pela ETSAB-UPC, pós-doutorado pela Università degli Studi di Napoli Federico II. Professora da Faculdade de Arquitetura e do Programa de Pós-Graduação em Arquitetura e Urbanismo da Universidade Federal da Bahia. E-mail: linabiba@yahoo.com
} 
THE TRACES OF MODERN HEALTHCARE ARCHI-

\section{TECTURES IN SALVADOR}

\section{Abstract}

The article presents briefly the architectures of healthcare in Salvador during the first half of the 20th century, all considered "modern". It specifies their initial characteristics, indicates briefly their importance and their current situations. For doing that the article uses a method that consists mainly in searching and interpreting documents through the "voluntary signs" (which are clear and repeated information left in a deliberate way in the documents) and through the "involuntary tracks" (that are more discreet and dispersed information left without clear intentions).

\section{LOS INDÍCIOS DE LAS ARQUITECTURAS MODER-} NAS DE SALUD DE SALVADOR

\section{Resumen}

El artículo presenta las arquitecturas de las instituciones de salud de Salvador durante la primera mitad del siglo XX, todas consideradas "modernas". Apunta sus características iniciales, indica brevemente sus importancias y sus situaciones actuales. Utiliza un método que consistente en la búsqueda y interpreteación de documentos a través de las "pistas voluntarias" Ique son informaciones claras y repetidas dejadas en los documentos de un modo deliberado) y de los "rastros involuntarios" (que son informaciones más discretas y dispersas dejadas sin intenciones precisas).

Palabras-claves: Historia. Arquitectura Moderna. Salvador.

Keywords: History. Modern Architecture. Salvador. 
"Eu gosto de catar o mínimo e o escondido. Onde ninguém mete o nariz, aí entra o meu, com a curiosidade estreita e aguda que descobre o encoberto." Machado de Assis

Em Salvador, existem arquiteturas que pertencem a diferentes momentos. Estão intactas, transformadas, arruinadas ou desaparecidas. Certas arquiteturas recebem reconhecimento e remetem à história da cidade e dos cidadãos. Mas a maior parte das arquiteturas soteropolitanas, especialmente aquelas realizadas no decorrer do século $X X$, são escassamente reconhecidas e pouco ou nada remetem às histórias locais. Mas, enquanto perdurem traços dessas arquiteturas, por mais precários que sejam, será possível recuperar as suas memórias para contar as suas histórias².

Para que se possa tratar de tais arquiteturas, aplica-se um método para acessar as informações contidas nos documentos. O método consiste na pesquisa e interpretação de pistas voluntárias e de rastros involuntários. Tal método se estrutura basicamente a partir das formulações teóricas de dois autores: Jeanne Marie Gagnebin e Carlo Ginzburg³.

2. Para maiores esclarecimentos sobre o método, vide: BIERRENBACH, Ana Carolina. Arquiteturas da recordação e do esquecimento: por um reconhecimento das manifestações modernas soteropolitanas. Salvador, ENCONTRO INTERNACIONAL ARQUIMEMÓRIA IV, 2013. Salvador, Anais..., 2013.

3. Carlo Ginzburg e Jeanne Marie Gagnebin referem-se à utilização desses rastros aparentemente irrelevantes para a reconstituição de diferentes circunstâncias. Ginzburg aponta a conformação de um método histórico "indiciário" que tem seus primórdios 
Pistas voluntárias são aquelas deixadas nos documentos de uma forma clara e repetida, com a intenção de perdurar e indicar determinados acontecimentos, tendendo a transmitir e consolidar sempre as mesmas histórias. A arquitetura se apresenta como um documento específico que possui uma forte conexão com as pistas voluntárias: é realizada com abundantes recursos e, supostamente, tem a capacidade de perdurar mais no decorrer do tempo do que outros tipos de documentos. Torna-se, assim, um meio oportuno para a transmissão e consolidação de certos conteúdos referentes àqueles que detêm poderes e influências.

Os rastros involuntários são aqueles que se apresentam nos documentos, de um modo discreto e disperso, demandando maior atenção por parte dos pesquisadores para que possam ser captados. Essa situação indica que tais rastros não têm a intenção de se fixarem enquanto pontos de referência capazes de se consolidarem historicamente. A arquitetura também porta em si a possibilidade de permitir acesso aos rastros involuntários. De qualquer modo, a utilização de um olhar atento é fundamental para possibilitar

\footnotetext{
no caçador que seria o primeiro a "narrar uma história, porque era o único capaz de ler, nas pistas mudas (se não imperceptíveis) deixadas pela presa, uma série coerente de eventos" (GINZBURG, 2012, p.152). Jeanne Marie Gagnebin também menciona a potencialidade do rastro: "é um fruto do acaso, da negligência, às vezes da violência; deixado por um animal que corre ou por um animal em fuga, ele denuncia uma presença ausente. (...). Rigorosamente falando, rastros não são criados (...) mas sim deixados e esquecidos" (GABNEBIN, 2006, p.113).
} 
que, a partir do reconhecimento dos rastros involuntários, aconteça a reconstituição de histórias que tendem a permanecer esquecidas.

Mas existe outra possibilidade: as pistas voluntárias podem se transformar em rastros involuntários. Isso acontece quando documentos produzidos com determinadas intenções passam a ser lidos a partir das suas contraposições, destacando outros elementos existentes que não são inicialmente previstos para aparecer e transmitir informações. São elementos incontrolados que despontam, tornando possível rastrear traços de outras histórias existentes por detrás das histórias mais notórias que pretendiam ser contadas. O texto usa o método mencionado para apresentar, de modo sintético, as arquiteturas das instituições de saúde realizadas em Salvador durante a primeira metade do século $X X^{4}$. Pretende-se apontar as suas características iniciais, indicar de forma sucinta as suas importâncias e assinalar as suas situações atuais ${ }^{5}$. Há que se considerar que, embora exista um incipiente reconhecimento das suas existências $^{6}$, tais arquiteturas continuam passando despercebidas tanto pelos historiadores quanto pelos cidadãos. É trabalho

4. O marco temporal do texto compreende o começo até meados do século $X X$.

5. Todos os títulos dos documentos consultados para o artigo são mantidos nas suas grafias originais. Entretanto, quando citados, optou-se por adotar a grafia atual, por ser impossível verificar a situação original da grafia de grande parte deles. 
do historiador descobrir essas histórias encobertas pelo descaso e pelo tempo.

Para acessar essas arquiteturas, parte-se de documentos diferenciados: por um lado estão os próprios edifícios remanescentes, fontes primárias privilegiadas de acesso tanto às pistas voluntárias quanto aos rastros involuntários. Por outro lado, há textos e imagens publicados principalmente em dois periódicos (A Tarde e Diário de Notícias), em algumas revistas (Etc, Rotary, Técnica, entre outras) e em alguns boletins médicos. Há que se salientar que a maioria dessas fontes é produzida por instituições públicas ou privadas detentoras de poderes e influências, que tendem a constituir e consolidar determinadas histórias. Mas, tal como indica Carlo Ginzburg, é possível chegar às experiências recalcadas da história a partir das suas próprias manifestações dominantes, que são justamente aquelas que têm maior possibilidade de perdurar no tempo. Ginzburg afirma que "ao escavar os textos, contra a intenção daqueles que o produzem, vozes incontroladas podem emergir"7.

6. O DOCOMOMO-BAHIA, atualmente coordenado pelo professor José Carlos Huapaya Espinoza, tem um papel importante para o reconhecimento da arquitetura moderna de Salvador. Também se destacam os trabalhos realizados por Anna Beatriz Galvão, Paulo Ormindo Azevedo, Nivaldo Andrade Júnior e Juliana Cardoso Nery. Uma importante referência sobre o tema pode ser consultada em Lins; Santana; Silva, 2012.

7. GINZBURG, Carlo. Threads and traces: true, false, fictive. Los Angeles/ Londres: University of California Press, 2012, p.3. Tradução da autora. 
Assim, trata-se de usar essas fontes tanto para extrair as pistas voluntárias quanto as involuntárias. Isso se torna necessário na medida em que fontes portadoras daqueles que têm poderes e influências mais escassos dificilmente se mantêm.

\section{Pistas Voluntárias}

Pistas voluntárias evocam a existência de um relevante aparato de saúde em Salvador, "com um acervo notável de obras" (MARGEM..., 1937, s/p) que conta com hospitais gerais, especializados e edifícios de assistência hospitalar. Tal acervo parece responder de forma apropriada às necessidades da população.

Existem notícias sobre a obtenção dos recursos, construções, inaugurações e usos desses edifícios. Mencionam-se os esforços e conquistas dos seus realizadores, que são entidades públicas ou particulares, sendo que em determinadas circunstâncias as duas atuam em parceria, com diferentes responsabilidades. As primeiras são compostas pelas diferentes escalas de poder, do municipal ao federal. As segundas contam muitas vezes com a participação de profissionais da saúde e instituições filantrópicas ${ }^{8}$.

A atuação de tais entidades particulares é indicada como fundamental para a estruturação do tratamento de algumas doenças, com a implementação de institutos de pesquisa e com a construção de edifícios. A tuberculose é uma dessas 
doenças que tem altíssima taxa de mortalidade na cidade e que possui entidades que assinalam a necessidade da instalação de dispensários, preventórios e sanatórios (SILVEIRA, 1937, p.18). O mesmo acontece com o problema do câncer, também com um obituário com cifras altas, o que indica a importância da construção de um hospital (IMPORTANTE..., 1940, s/p). A proteção à maternidade e à infância também é foco de atenção, com a recomendação de uma estrutura que deve comportar maternidades, hospitais infantis, abrigos maternais, pupileiras, escolas de puericultura, creches e lactários (SILVEIRA, 1937). Nos documentos há referências a hospitais gerais, tanto públicos quanto particulares.

Entre os primeiros está o "imponente" (CONSTRUCÇÃO..., 1935, s/p) Hospital de Pronto Socorro (ou Hospital Getúlio Vargas) ${ }^{9}$ (Figura 2). Localizado no bairro do Canela, é

8. Com relação ao papel institucional, a partir do primeiro período Vargas (19301945), o governo atua por meio de um modelo centralizador com políticas de saúde pensadas de modo unificado e com aplicações nacionais a partir de diretrizes do Ministério da Educação e Saúde. Tal estrutura se mantém no governo Dutra e no segundo governo Vargas, embora cada qual apresente especificidades (COSTA (2011, p.6); HOCHMAN (2005, p.131)). No plano federal a Divisão de Obras do Ministério da Saúde define as diretrizes dos edifícios em todo o país (COSTA, 2011, p.17). Sua atuação estabelece programas arquitetônicos, especifica orçamentos, executa e fiscaliza obras.

9. Arquiteto Chefe da Prefeitura do Distrito Federal. Cia. Construtora Nacional. Inauguração - 18/09/1941. (CIA. CONSTRUTORA..., 1936), (CONSTRUÇÃO, 1935) e (SERÁ..., 1941). 
construído em "obediência aos rigores da exigência técnica, quer do ponto de vista arquitetônico, quer do higiênico" (É UMA..., 1936, s/p), dispondo de "amplas e magníficas acomodações" (QUE..., 1938, s/p). O hospital concentra-se em um único bloco em formato aproximado a um "H", que conta com uma composição escalonar. A fachada principal do edifício apresenta poucos sinais de ornamentação: por um lado articula elementos que possuem dimensões horizontais e verticais, como frisos e colunas; por outro apresenta um equilíbrio entre partes cheias e vazias, a primeira conformada pelas janelas ritmadas, e a segunda, pelos amplos terraços.

Mas o maior destaque fica para o "grandioso" (PAPEL..., 1948, p.3) Hospital das Clínicas (atual Hospital Universitário Edgard Santos - HUPES) ${ }^{10}$ (Figura 1), situado nas proximidades do Pronto Socorro. Afirma-se que "é construído dentro da técnica moderna, indispensável para a maior imponência e perfeição do edifício" (MARGEM..., 1937, s/p). Sua implantação também assume aproximadamente a forma de um " $\mathrm{H}$ ", possuindo uma ala central e quatro alas laterais. Com uma composição escalonar, há uma especial atenção na solução dos cruzamentos e das extremidades

10. Arquiteto Hyppolito G.Pujol Jr., sob as diretrizes do Engenheiro Ernesto Campos; Construtora Emílio Odebrecht. Pedra fundamental - 19/10/1937; inauguração - 22/11/1948 (COSTA (2010), MARGEM... (1937) e REVESTIRSE-Á... (1937, s/p)). 


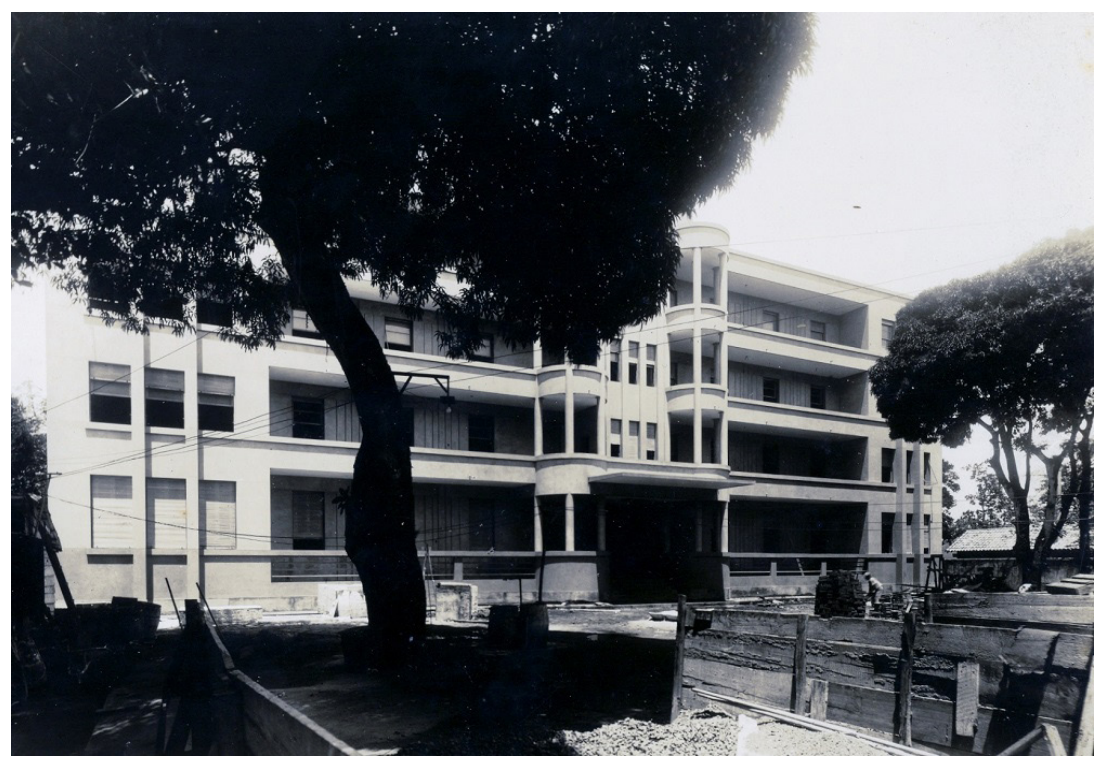

Figura 1 - Fachada Principal do Pronto Socorro, s/d. Fonte - HUPES

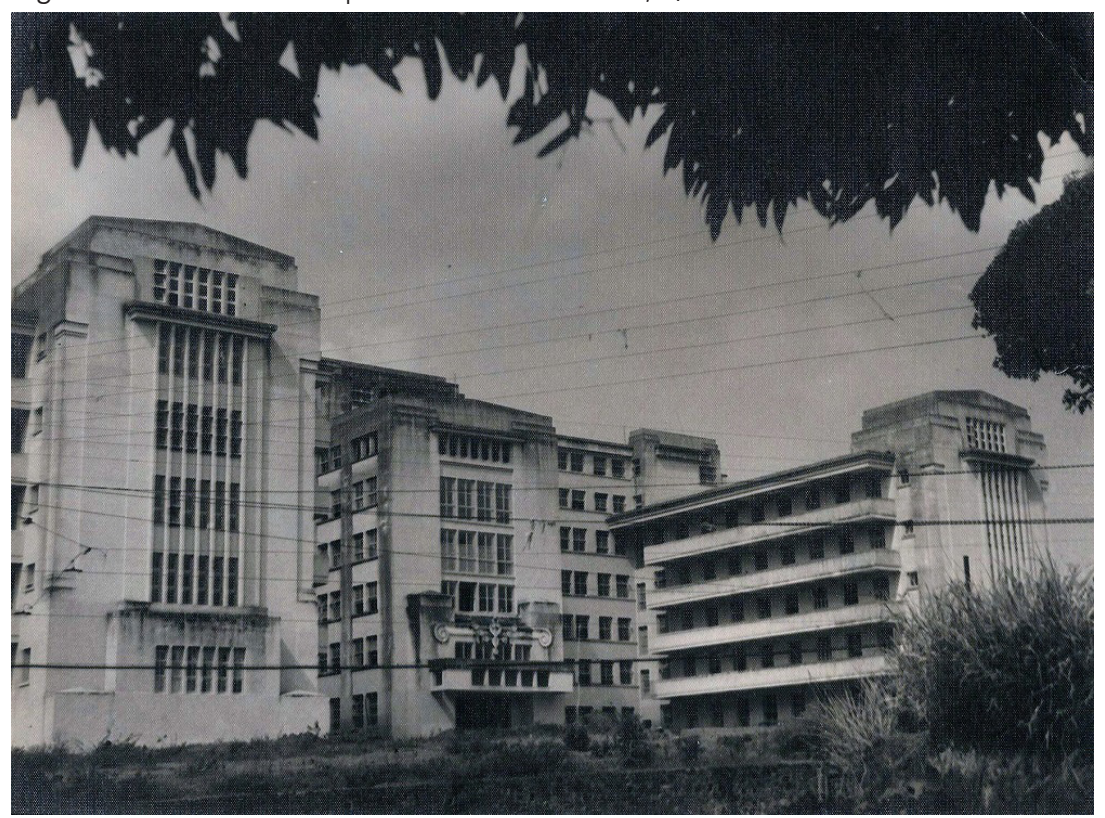

Figura 2 - Fachada principal do Hospital das Clínicas, s/d. Fonte - HUPES 
das suas alas. Na ala central destaca-se um corpo que possui na sua parte posterior um auditório semicircular e na parte frontal a entrada principal do edifício. Essa última possui uma ornamentação que adota volutas de inspiração art déco. Nas alas laterais não há ornamentação. Suas fachadas também são marcadas pela presença de janelas ritmadas e por extensos terraços contínuos que oferecem ao edifício uma horizontalidade predominante. Trata-se de um edifício monumental que possui um enorme impacto no seu entorno.

O Hospital Português ${ }^{11}$ (figura 3) é instalado inicialmente na Colina do Bomfim. Nos anos 1930 é transferido para o "aristocrático" bairro da Graça, ocupando um casarão que é adaptado para o uso hospitalar e modernizado, adotando na sua fachada principal uma platibanda escalonada. No final da mesma década realiza-se, ao seu lado, um "magnífico" bloco com "salas amplas e arejadas", que possui, por sua vez, uma volumetria escalonada. Tal recurso possibilita que os dois blocos estabeleçam um diálogo entre seus elementos escalonados. Segundo notícias, o edifício mais recente tem uma "bela fachada, muito simples" (OBRA..., 1938, $\mathrm{s} / \mathrm{p})$. De fato, quase não conta com decorações, apresentando apenas um friso que separa a sua base e seu corpo

11. Construtora Odebrecht. Adaptação do bloco antigo - 08/03/1931; inauguração novo bloco - 29/05/1938; inauguração do bloco modernista da maternidade 1957 (OBRA, 1938). 
e circunda a escadaria.

Hospital Manoel Victorino ${ }^{12}$, localizado no bairro de Nazaré, nas proximidades de outros importantes hospitais, é considerado "uma organização modelar, (...) no tipo dos hospitais modernos, de belo aspecto arquitetônico" (ÁLBUM..., 1954, s/p). Com uma implantação em “L" o edifício apresenta uma solução que recorre ao modernismo. As fachadas laterais se estabelecem com uma modulação ritmada, sendo que uma delas, as estruturas dos módulos, assume um aspecto de brises, elemento também presente na terceira fachada.

Além dos hospitais gerais, há também a notória presença de hospitais especializados e de outras instalações relacionadas com a saúde pública.

Na "bucólica paisagem" de Brotas (INSTITUTO..., 1940) encontra-se o Hospital Aristides Maltez ${ }^{13}$ (Figura 4). Destinado ao tratamento e internamento de pacientes cancerosos e aos estudos em torno da moléstia (BAHIA..., 1951, s/p),

12. Arquiteto Flávio Amílcar Régis do Nascimento. Construtora Régis Agostin. Inauguração - 30/01/1951; obras concluídas - 1954 (ANDRADE JÚNIOR (2011, p.135), CENTENÁRIO (1997) e ÁLBUM (1954)).

13. Arquiteto Luiz Arantes, sob diretrizes de Ernesto Campos. Consultoria de Hélio Duarte. Eng. Belmiro Silva. Pedra Fundamental - 25/10/1940; início das obras - 1945; inauguração primeira ala - 02/01/1952 e inauguração da segunda ala - 22/05/1956; conclusão das obras - 1984. Pavilhão Landulfo Alves - inauguração 1963 (INSTITUTO, 1940, HOSPITAL, 1992, MALTEZ, 1957 e SECRETARIA, 1940). 


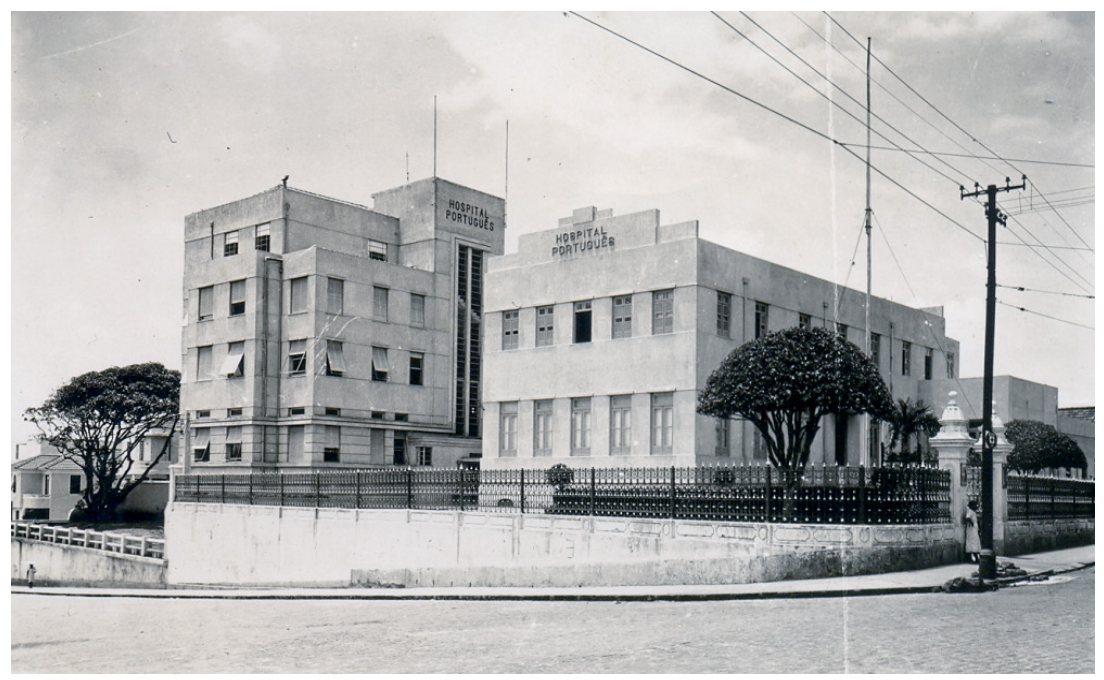

Figura 3 - Pavilhões do Hospital Português, s/d. Fonte - Arquivo Histórico do Município de Salvador/FGM.

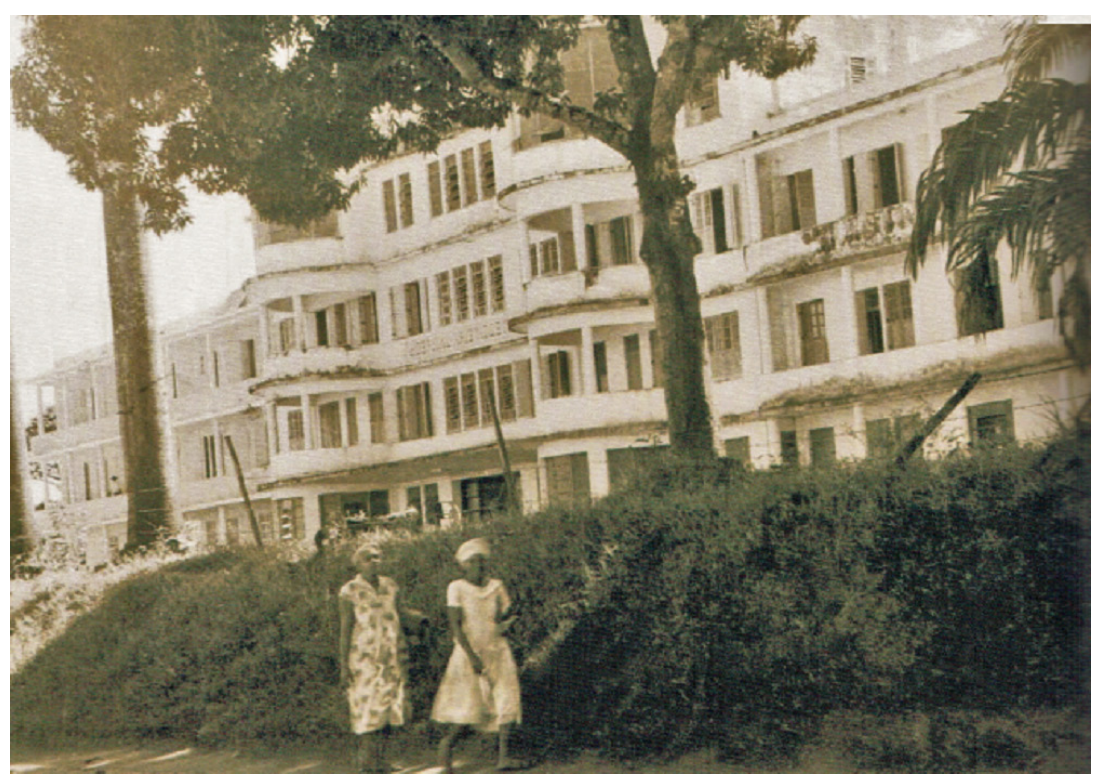

Figura 4 - Hospital Aristides Maltez, s/d - HAM 
preenche "os requisitos técnicos de um Hospital Moderno" (22 ANOS..., 1959). Apresenta inicialmente um monobloco longitudinal em formato de "I" ao qual se adere na parte posterior um volume irregular que corresponde à circulação vertical. Na parte frontal, apresenta um volume central mais alto com pequenas janelas enfileiradas, delimitado por dois volumes cilíndricos que são fechados por vidraças nas suas partes inferiores e superiores e abertos com a presença de pilotis circulares nas partes intermediárias. Nas partes laterais, apresenta extensas varandas abertas, cuja horizontalidade é minimizada pela presença repetida de outros pilotis circulares. O edifício possui semelhanças com o Pronto Socorro.

Quanto ao tratamento da tuberculose, aparece o Preventório Santa Terezinha ${ }^{14}$, situado no "salubérrimo arrabalde" de Brotas (PREVENTÓRIO..., 1936, s/p) (figura 5), destinado aos filhos de tuberculosos. Afirma-se que está instalado "dentro da técnica, de modo a propiciar todo o conforto aos seus internados e a atender, perfeitamente, à finalidade a que se propõe" (FUNDAÇÃO..., 1945, p.9). Conta com um extenso bloco horizontal que assume praticamente uma forma em "I", com dois andares do qual se destacam balcões lineares cobertos com marquises que correspondem aos solários, que marcam a horizontalidade predominante,

14. Em obras em 1936; inauguração - 17/05/1945. Acervo HEOM, (MACHADO (2007, p. 198) e PREVENTÓRIO... (1936)). 
amenizada apenas pela cadência da fenestração. Demarca-se a entrada principal por um volume canelado disposto da cobertura. Por meio desses recursos concebe-se um edifício que tem semelhanças com o Pronto Socorro e com o Hospital A. Maltez.

Mas o edifício mais referenciado para o tratamento da tuberculose é certamente o "moderníssimo" (UM RÓL..., 1938, $\mathrm{s} / \mathrm{p})$ Hospital SantaTerezinha (atual Hospital Especializado Octávio Mangabeira - HEOM) (figura 6) ${ }^{15}$, localizado no subúrbio da cidade, no bairro do Pau Miúdo. O hospital pretende dispor "de todos os recursos exigidos pela técnica moderna" (SECRETARIA DE EDUCAÇÃO E SAÚDE, 1940, $\mathrm{s} / \mathrm{p})$. Alega-se que a concepção do edifício está "destinada a atender às suas verdadeiras necessidades, por isso a sua edificação obedeceu aos mais exigentes requisitos da ciência" (HOSPITAL..., 1941, s/p). Essa correspondência com as demandas científicas começa com a própria escolha da área "vasta e aprazível" (NÃO..., 1938, s/p) onde é construído, que conta com a constante presença de ventilação e insolação demandada para os sanatórios.

Inicialmente o Hospital se conforma a partir de um bloco principal que possui três blocos secundários associados, assumindo uma forma aproximada de um "E". O progra-

15. Atribuído ao Eng. Souza Aguiar. Construtora Emílio Odebrecht. Início das obras - 25/04/1937; conclusão das obras, 15/09/1941; inauguração - 03/01/1942 (MAIS..., 1944). 
ma pretende responder às demandas de atendimento $\mathrm{e}$ internação dos doentes de um modo "sóbrio e eficiente" (SILVEIRA, 1937, p.22). Os leitos de enfermarias são determinantes para a conformação do bloco principal: nos dois primeiros pavimentos são atendidas as classes sociais mais baixas com enfermarias maiores; no terceiro pavimento, as enfermarias tornam-se menores para receber os pacientes de baixa renda que precisam de maior isolamento; no quarto pavimento são ainda menores, com apenas um leito, destinadas a atender pacientes de classes sociais mais altas. Essa situação afeta a conformação volumétrica do edifício, que se torna mais estreito nos pavimentos superiores. O volume é demarcado por linhas horizontais e extremidades curvas que correspondem aos solários. $\mathrm{Na}$ parte central da edificação, o volume principal apresenta um recuo e uma marquise marca a sua entrada principal. 0 edifício conforma-se assim com a "simplicidade e modéstia" (SILVEIRA, 1937, p.23) buscadas inicialmente.

Para combater a doença, difunde-se a construção da denominada "Cidade dos Tuberculosos", no entorno do Hospital Santa Terezinha. Trata-se de uma obra "de vulto", que pretende "comportar todos os serviços técnicos exigidos para o tratamento ou averiguações da doença" (MAIS..., 1974, $\mathrm{s} / \mathrm{p})$. Segundo Andrade Júnior, surgem para isso o Sanatório de Triagem, o Pavilhão de Triagem, o Pavilhão de Serviços Gerais ${ }^{16}$ e o Dispensário da Cruz Vermelha ${ }^{17}$. 


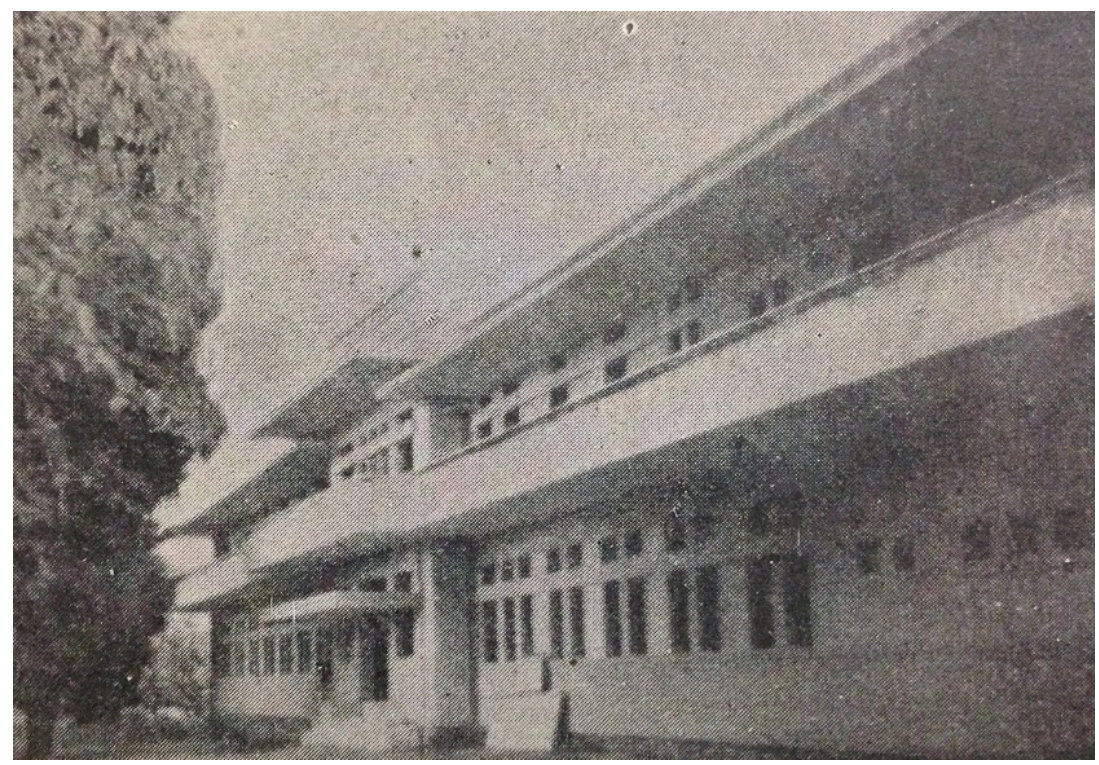

Figura 5 - Preventório Sta. Terezinha. Fonte - (FUNDAÇÃO, 1945, p.7).

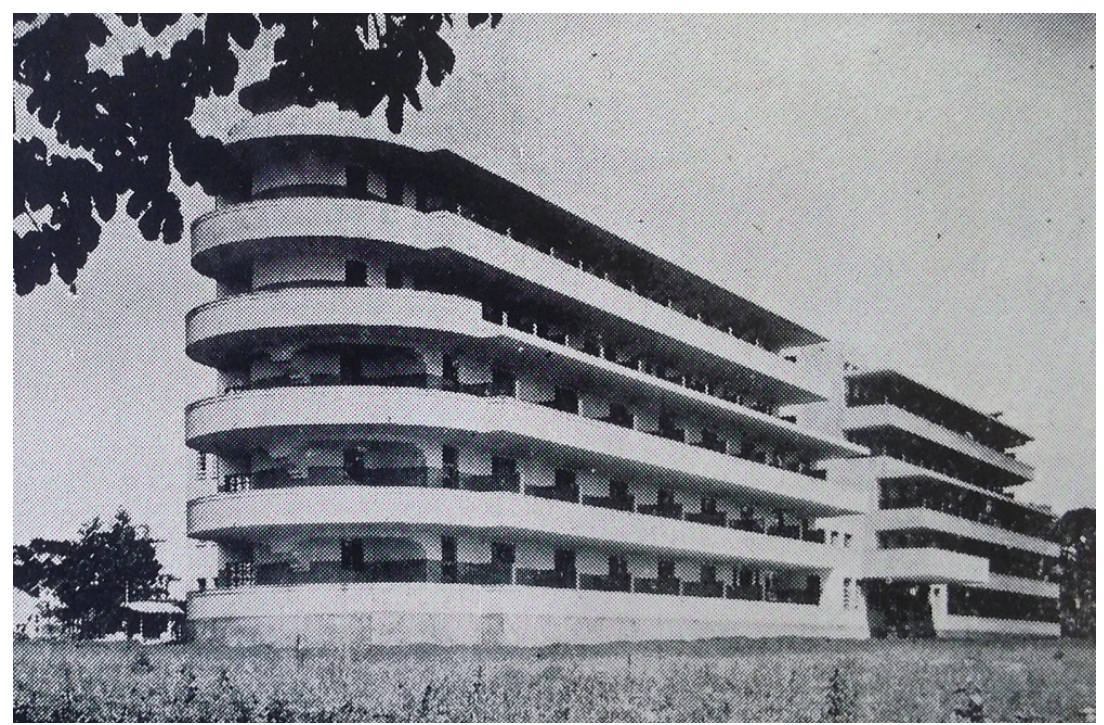

Figura 6 - Hospital Santa Terezinha. Fonte - (SECRETARIA DE EDUCAÇÃO E SAÚDE. ESTADO DA BAHIA, 1940, s/p) 
Esses blocos, todos com formatos semelhantes a um " $\mathrm{H}$ ", são considerados "construções simples, porém completas", que se conformam a partir de padrões do modernismo com edifícios que se apresentam em blocos articulados por rampas ou passarelas, com janelas em fita e pilotis. Tais construções "obedecem ao plano que está sendo seguido nacionalmente" (COLABORA..., 1947, s/p).

\section{O "modelar" (ENTREGA, 1944, s/p) Instituto Brasileiro} para Investigação da Tuberculose - IBIT ${ }^{18}$ (Figura 7) também é salientado pelos documentos. Tem inicialmente um projeto com um caráter monumental, mas o edifício, que é finalmente construído no Calabar, possui características mais modestas. Acomoda-se em um "salutar" terreno inclinado de esquina e conta com um programa considerado sem precedentes (SILVEIRA, 1971, p.58), mas que acaba por conquistar "instalações adequadas" (PRIMEIRO..., 1939, p.02). A distribuição do edifício procura atender as suas necessidades funcionais contendo espaços destina-

16. Arquitetos Diógenes Rebouças e Jorge Machado Moreira (Sanatório de Triagem). Inaugurações referenciadas nos dias 27/01/1951 e 02/07/1952 (ANDRADE JR, 2011, p.125, COMBATE, 1952, p.2).

17. Arquitetos Newton Secchin e Pedro Rossi. Pedra fundamental - 29/10/1948 (PROTEÇÃO, 1948, s/p); inauguração 27/01/1951 (ANDRADE JÚNIOR, 2011, p. 125).

18. Obra do "fabuloso" Arquiteto Hélio Duarte, Companhia Brasileira imobiliária de Construções. Início das obras 05/11/1942; inauguração 29/09/1944. Vide Silveira (1971, p.76). 
dos à assistência aos tuberculosos, profilaxia da doença, ensino e preparo de técnicos especialistas e pesquisa (SILVEIRA, 1977, p.65). Possui inicialmente um bloco único com volumetria irregular e com a presença de linhas retas e curvas. As aberturas da fachada não respondem a nenhuma composição, mas às necessidades dos ambientes internos. Tal solução arquitetônica corresponde aos procedimentos arquitetônicos adotados por Duarte que, segundo Silveira, "não se preocupa com a fachada, mas sim com a essência do edifício" (SILVEIRA, 1971, p.59). E a sua essência é resumida como uma obra modesta, acanhada, mas, sobretudo, com "excelente funcionalidade" (SILVEIRA, 1971, p.65). É um edifício que responde tanto às suas demandas de uso quanto às características do terreno no qual está situado.

O projeto da Clínica Tisiológica da UFBA ${ }^{19}$ é apresentado como um local destinado a formar "os técnicos para o combate de um dos maiores flagelos da humanidade" (GRANDE, 1952, p.02). Afirma-se que o edifício é realizado "dentro dos melhores padrões técnicos" (ÁLBUM..., 1954, $\mathrm{s} / \mathrm{p})$. Apresenta um volume único que adquire uma forma aproximada a um "I", com a inserção de um volume anexo

19. Arquitetos Alexandre Costa Neto, Newton Secchin, Marcos Studart e Leslie R. Inke. Início das obras - 1950; informação sobre inauguração com duas datas: 27/01/1951 (Andrade Júnior, 2011, p.133) ou 16/10/1952 (GRANDE..., 1952, p.02). Ver também Clínica... (1957, p. 244-245). 
no nível do térreo. Na fachada principal destacam-se o ritmo estrutural e a presença de partes cheias e vazias, relacionando-se claramente com os princípios do modernismo, sendo um exemplo significativo.

Para a atenção às mães e às crianças, nos documentos aparecem referências a um amplo aparato de instalações de saúde que consistem em maternidades e hospitais. E há também inúmeras menções à assistência para a maternidade e infância com a presença de abrigos maternais, pupileiras, lactários e as escolas de puericultura, referidos anteriormente.

Concebe-se no princípio do século XX a "grandiosa" (MATERNIDADE, apud AMARAL, 2005, p.58) Maternidade

Climério Azevedo $^{20}$, instalada no bairro de Nazaré. Trata-se de um edifício que recebe mães carentes e pensionistas e pretende seguir "as exigências científicas mais modernas" (MATERNIDADE, apud AMARAL, 2005, p.53-54). Na sua primeira fase realiza-se uma maternidade composta por "diversos pavilhões, construídos com todos os requisitos indispensáveis a uma boa higiene, ligados pela face interna por largas varandas cobertas, circunscrevendo áreas ajardinadas e formando um belo conjunto que dá ao visitante a

20. Companhia Construtora Nacional. Inauguração - 1935; bloco antigo - inauguração - 30/10/1910. (COMPANHIA (1935), MATERNIDADE (apud AMARAL, 2005, p.58), NOTÁVEL... (1936, p.08)). 
impressão alegre e sadia, que deve ser de grande conforto às parturientes que ali procuram assistência" (REFORMA, apud AMARAL, p.58). Realiza-se um edifício com referências ecléticas, que embora apresente decorações mais simplificadas, mantém frontões triangulares e curvos adornados. Com o tempo, torna-se necessária a ampliação da maternidade e constrói-se o "sóbrio e moderno" pavilhão para pensionistas (figura 8). O novo pavilhão rompe com a continuidade dos anteriores e é construído isoladamente, com um partido em "E". É um edifício que parte de uma composição e que possui elementos claramente inspirados

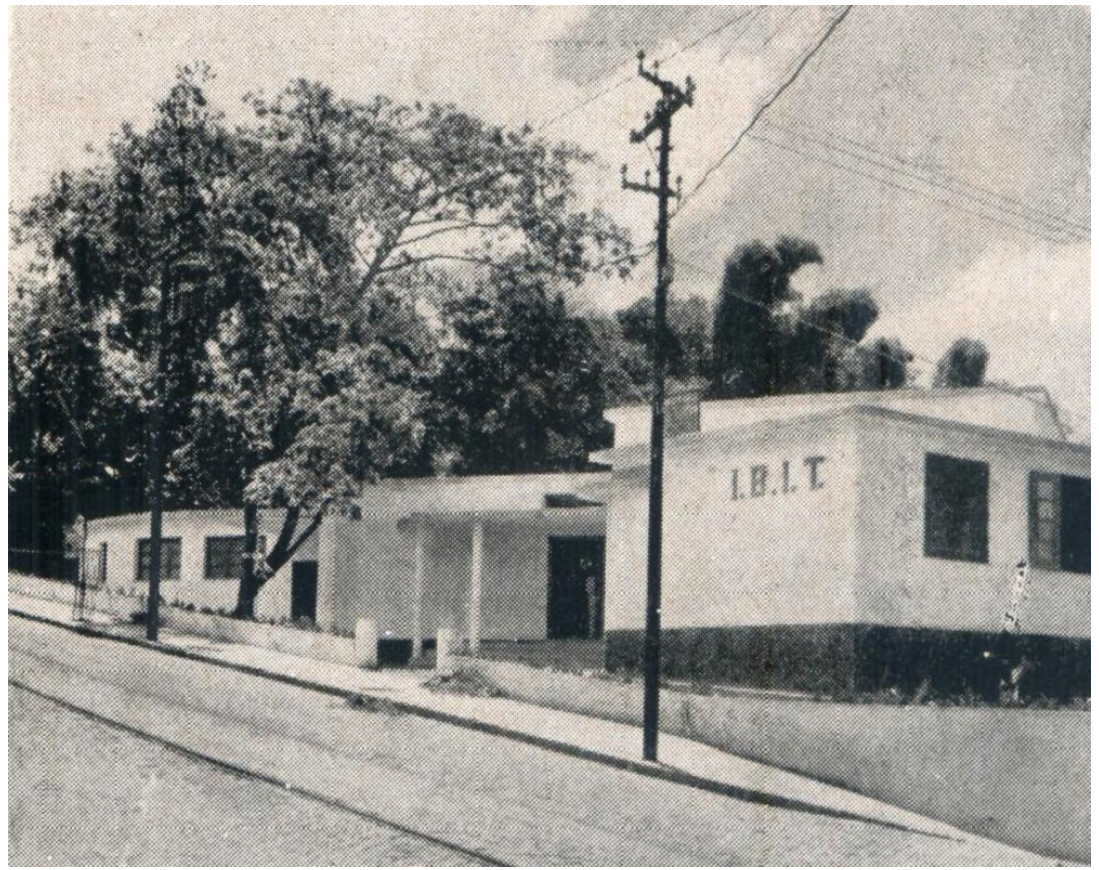

Figura 7 - Fachada principal do IBIT, s/d. Fonte - (CARICCHIO, 1946, s/p) 


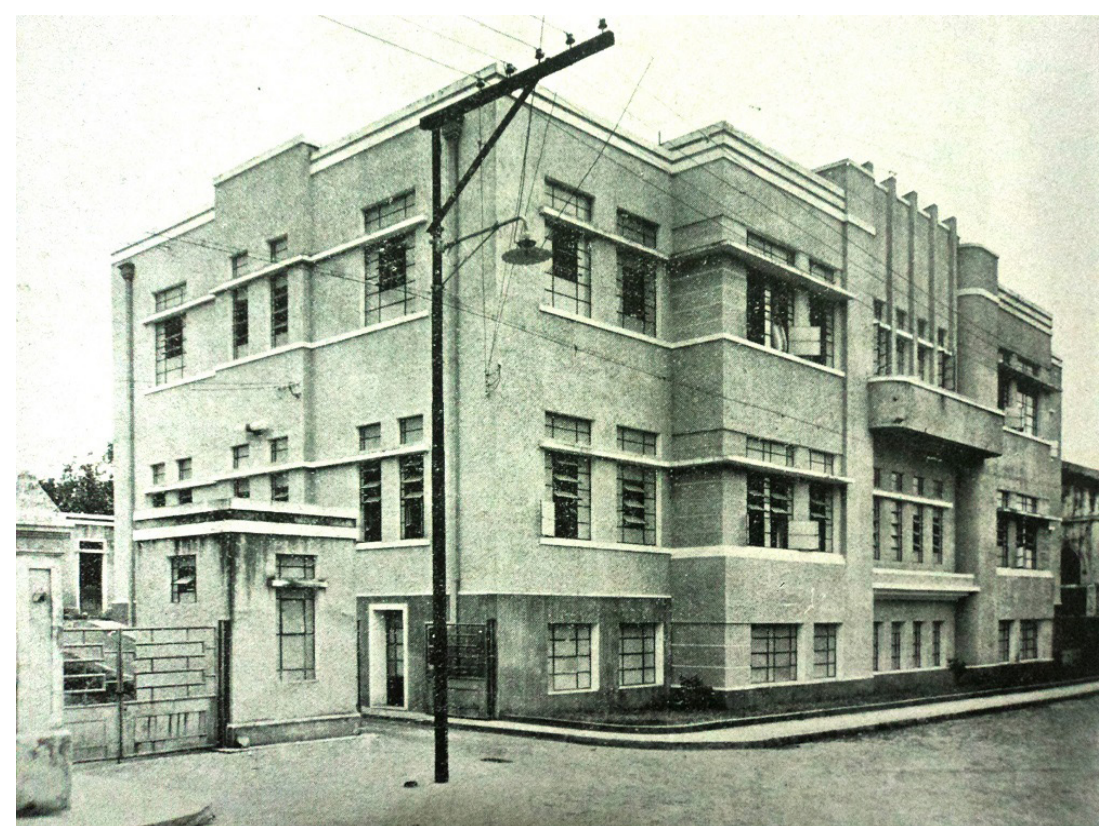

Figura 8 - Fachada Pavilhão Hospital Climério Azevedo. Fonte - (ROTARY..., 1937, s/p.)

no art déco.

Para as crianças, realiza-se o Hospital Alfredo MagaIhães (também conhecido como Hospital das Crianças)"21, construído no alto do Morro do Menino Jesus, no bairro do Rio Vermelho, "à beira-mar" (PRÓ PARVULUS, 1935, p.02). Trata-se de um hospital que se pretende "modesto, porém moderno", mas que termina assumindo um caráter monumental (MAGALHÃES, apud SANTOS, 2014, p.116).

21. Engenheiro Julio Conti. Início das obras - 1923; inauguração do primeiro pavilhão - 25/12/1936; instalação da maternidade - 31/01/1952 (INSTITUTO DE PROTEÇÃO E ASSISTÊNCIA À INFÂNCIA NA BAHIA (1935), Leite (1952) e Santos (2014, p.132)). 
Destina-se ao tratamento de crianças com doenças infectocontagiosas e é concebido a partir de um sistema de pavilhões para diferentes especialidades, com possibilidades de ampliações no decorrer do tempo (MAGALHÃES, apud SANTOS, 2014, p.115). No princípio dos anos 1950, um dos pavilhões é adaptado para se tornar uma maternidade "destinada verdadeiramente às gestantes pobres" (LEITE, 1952, $\mathrm{s} / \mathrm{p})$. Entretanto, o conjunto acaba contando com apenas 3 pavilhões que isoladamente se apresentam com as formas em "I", mas se articulam entre si formando um "U,", ao redor de um jardim. O edifício frontal é mais compacto e os outros dois laterais são mais extensos, contando ambos com terraços correspondentes a solários. Não há uma acentuação da horizontalidade dos edifícios e sim uma demarcação de um ritmo vertical pela repetição de colunas nos terraços. Entre os elementos que podem ser encontrados no edifício estão colunas clássicas e frontões estilizados.

No bairro do Tororó é instalado o "moderno" (OBRAS, 1952) Hospital Martagão Gesteira (antigo Hospital de Crianças da Liga Baiana contra mortalidade infantil) ${ }^{22}$, que tem como missão aumentar o número de leitos para crianças pequenas e prematuras. É implantado sobre uma grande plataforma com volumes articulados, conformando aproximada-

22. Arquiteto Hélio Duarte. Companhia Brasileira Imobiliária e de Construções. Pedra fundamental - 02/1951; inauguração apontada em 1965 (ANDRADE,2011, p. 118) e 1967 LIONS (1968, p.85)). 
mente um "L" O volume frontal é um paralelepípedo baixo, com dois andares. A sua fachada principal é formada pelo andar inferior apresentando pilotis destacados ao centro, parcialmente camuflados à esquerda e integrados com as janelas à direita. $O$ volume posterior é mais alto e apresenta uma solução de fachadas diferente, com janelas em fita. Apresenta claras referências do modernismo.

As pistas voluntárias assinalam principalmente os aspectos monumentais e imponentes dos edifícios, mas também comparecem edifícios mais simples e modestos. A existência de edifícios com fachadas decoradas é considerada pelas fontes consultadas como positiva, mas o mesmo pode ser dito daquelas fachadas com pouca ou nenhuma decoração. Todas as soluções arquitetônicas e todos os estilos são considerados igualmente válidos.

Constantemente as soluções arquitetônicas são citadas como "modernas", realizadas a partir de respostas às demandas de caráter "técnico" ou "científico". No âmbito técnico e científico, indicam-se tanto os equipamentos instalados nas instituições de saúde quanto as próprias soluções arquitetônicas adotadas, que, de acordo com as fontes, primam por ser cômodas, ventiladas e higiênicas. Assinala-se também a presença de um moderno sistema de saúde que, de um modo econômico, eficiente e racional, é supostamente capaz de responder às demandas de todos os estratos da população. 
Outro elemento que se identifica é a menção ao caráter "modelar" de edifícios que pretendem dar exemplo para outros. Em determinados documentos se indica também que certos edifícios, por sua vez, são realizados a partir dos parâmetros fornecidos por outros, o que demonstra a aplicação dos modelos difundidos no âmbito nacional e aplicados na Bahia. De fato, há correspondências entre as soluções aplicadas nacionalmente e aquelas usadas localmente. Nota-se a progressiva superação dos sistemas de múltiplos blocos para a construção de blocos independentes (COSTA, 2010), que passam a ser indicados como a melhor forma para reduzir infecções e obter benefícios funcionais e econômicos (MINISTÉRIO DA SAÚDE, 1965). Aparecem assim soluções que seguem partidos em " $H$ " (Hospital das Clínicas, Pronto Socorro, etc.), em "I" (Hospital Aristides Maltez, Preventório Santa Terezinha, etc.); em "E" (Hospital Santa Terezinha, novo bloco da Maternidade Climério Azevedo).

\section{Pistas Involuntárias}

Há poucos documentos indicando a existência de outras instalações de saúde em Salvador. Não há muitas notícias sobre a obtenção de recursos, as construções, inaugurações e usos, mesmo que alguns dos edifícios tenham dimensões consideráveis e pareçam ser relevantes para a cidade. Alguns edifícios ainda estão erguidos e outros já 
foram demolidos. Certamente uma pesquisa mais aprofundada poderia revelar outras pistas voluntárias, mas interessa aqui tratar dos rastros involuntários detectados de certos edifícios, encontrados de modo discreto e disperso nos documentos, aparecendo usualmente em pequenas notas nos jornais, revistas e boletins, geralmente com poucas imagens.

Pode-se dizer isso sobre o "majestoso templo" (SAMPAIO, 1928, p.124) do Hospital Espanhol ${ }^{23}$ (Figura 9) que se situa em "um dos melhores pontos da cidade" (EDIFíclO..., 1933, s/p), em uma colina no Porto da Barra. O edifício possui uma arquitetura eclética e adquire um aspecto monumental devido à sua implantação e à presença de duas torres que se posicionam diante da vista para o mar. Posteriormente, recebe uma ampliação que adere plenamente ao modernismo.

O mesmo vale para o Hospital Ana Nery (anterior hospital do Instituto de Aposentadoria e Pensões dos Empregados em Transportes e Cargas - (APETC) ${ }^{24}$, que apesar de ser monumental, é pouco citado pelos documentos. Localizado entre os bairros da Caixa d'Água e o Largo dos Queimados,

23. Inauguração no princípio do século XX. Atualmente o complexo encontra-se desativado.

24. Atribuído ao arquiteto Moacyr Fraga. Pedra fundamental - 02/07/1947 (SOUZA, 2015, P.07); inauguração do setor de cardiologia - 1962 (ANDRADE JÚNIOR, 2011, p.128). 


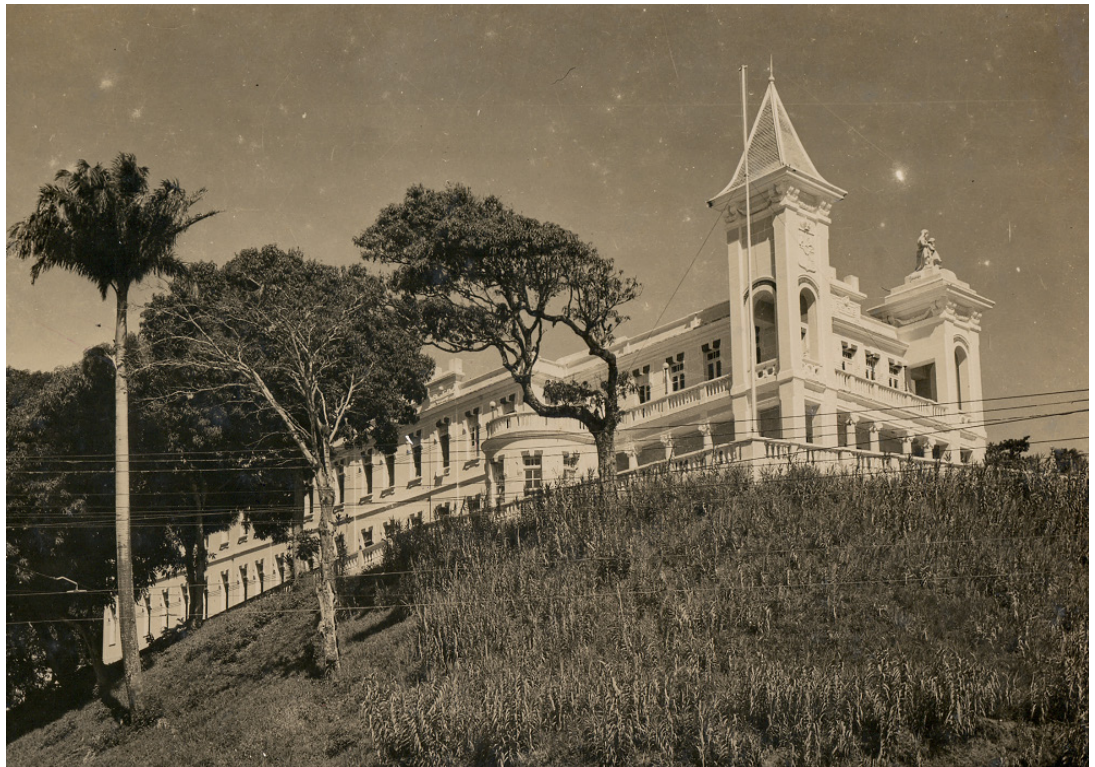

Figura 9 - Hospital Espanhol, s/d. Fonte - Arquivo Histórico do Município de Salvador/FGM

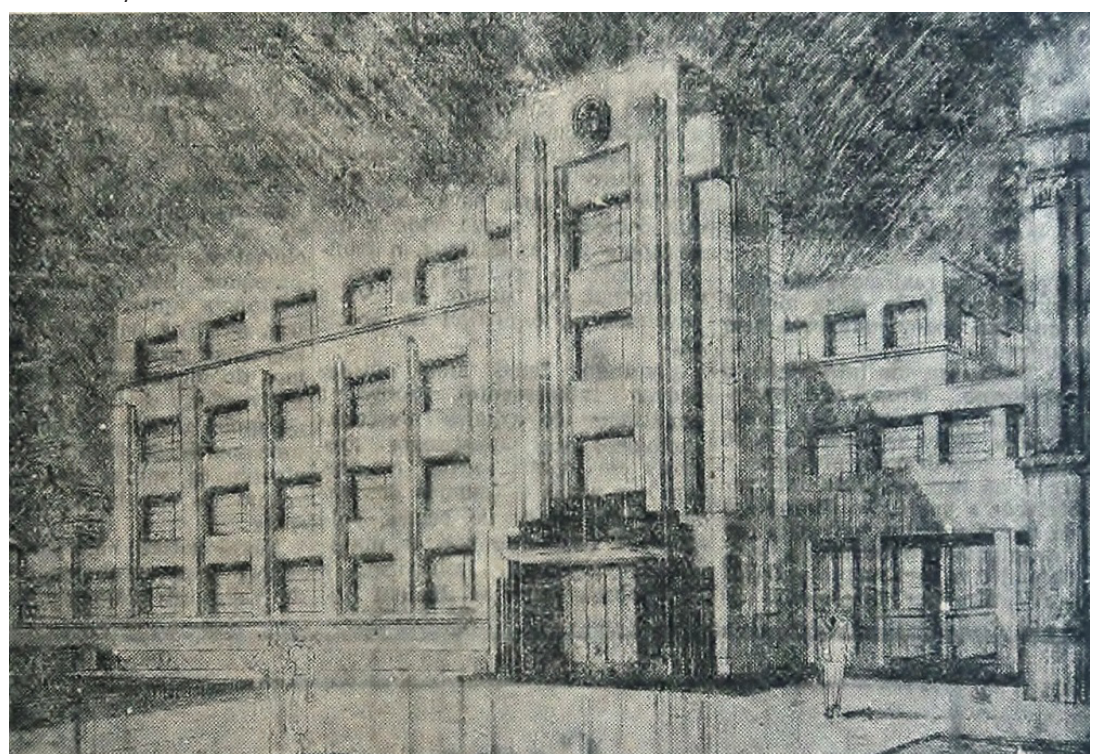

Figura 10 - Ambulatório Silva Lima. Fonte - (OBRA BENEMÉRITA..., 1938, s/p) 
também se posiciona em uma colina. Apresenta um monobloco em formato aproximado a um "I", cuja parte central se destaca em dimensão e em altura, sinalizando o acesso principal. É exatamente nesse ponto que o edifício, no demais isento de ornamentação, recebe óculos e caneluras que fazem referências às colunas clássicas. Afirma-se que o edifício se pauta naquele realizado no Rio de Janeiro para IAPETC, fato que parece corresponder à realidade, uma vez que os dois hospitais possuem aspectos muito semelhantes (ANDRADE (2012, p. 241); SOUZA (2015, p.6)).

No entorno do Hospital Santa Izabel, cujo edifício principal é construído no final do século XIX, ergue-se o novo paviIhão do ambulatório Silva Lima ${ }^{25}$ (Figura 10). Embora se afirme que é uma obra "vultuosa", há poucos documentos sobre esse edifício. Conforma-se como um pavilhão a mais do hospital, com partido aproximado a um " $\mathrm{H}$ " e conta com uma composição escalonada e frisos verticais que o relacionam a uma estética art déco.

Com relação ao tratamento da tuberculose, há notícias dispersas sobre outros equipamentos instalados na cidade. É o caso do primeiro Dispensário que aparece para o tratamento da "peste branca" na cidade, denominado Ramiro Azevedo ${ }^{26}$, que possui uma estrutura modesta no Campo da Pólvora. Durante muitos anos permanece em estado de

25. Companhia Brasileira de Construção. Pedra fundamental $-24 / 02 / 1938$. Vide Obra Benemérita... (1938, s/p). 
abandono, mas "ressurgiu das ruínas a que chegara, ampliado, provido de novas instalações" (PREVENTÓRIO..., 1939, p.25). Trata-se de um pequeno edifício que ainda utiliza uma composição tradicional, com formato de " $U$ ", que mantém colunas clássicas e elementos decorativos.

No contexto do Hospital Santa Terezinha realiza-se um primeiro anexo para ampliar sua capacidade, sobre o qual há poucas referências. Trata-se do Pavilhão Hélio Marchado $^{27}$ para o tratamento de crianças (PROTEÇÃO, 1948). Também se constitui como um bloco único com dois andares e extremidades curvas que seguem as características do sanatório.

Para completar, há também rastros de dois outros hospitais especializados. O primeiro é o Hospital Juliano Moreira (antes denominado São João de Deus) para o tratamento de doentes mentais, em Brotas. As referências sobre o pavilhão destinado aos pensionistas de sexo masculino do pavilhão Aristides Novis ${ }^{28}$ são poucas (JACOBINA, 2001, p.305). É um edifício isolado que utiliza recursos inspirados no art déco.

A mesma inspiração orienta o projeto do Hospital Santa

\footnotetext{
26. Início das obras - 1907; Primeira inauguração - 14/09/1919; reinauguração 29/05/1937 (MACHADO (2007, p. 198) e SILVEIRA (1937, p.16)).

27. Inauguração - 28/10/1948 (PROTEÇÃO, 1948, s/p).

28. O Asilo São João de Deus existe desde 1874 (JACOBINA, p.209). Inauguração do Pavilhão Aristides Novis - 1936 (JACOBINA, p.305).
} 
Luzia $^{29}$, nas proximidades do Hospital Santa Izabel. O edifício, pretende "agasalhar os doentes de visão", e tem um "belo prédio" cuja planta segue "os preceitos da ciência", possuindo "linhas modernas" (VAI..., 1938, s/p). Não há como confirmar se o projeto é de fato realizado segundo tais indicações.

Pistas voluntárias encontradas na maior parte dos documentos apontam a existência de um sistema de saúde moderno, eficiente e racional que atende de modo apropriado a todas as camadas da população local e que pretende expandir-se pelas principais cidades do Estado, obedecendo a uma mesma orientação central (CONSTRUÇÃO..., 1935). Mas, a partir da observação atenta das entrelinhas e notas de rodapé dos documentos, pode-se detectar uma situação contraposta: indica-se que embora tal sistema de saúde possa até existir na capital, não possui um alcance suficiente, e não prima pela eficiência ou pela racionalidade. É o que demonstra o seguinte trecho de um documento, afirmando que o referido sistema de saúde é incapaz de atender à população da cidade de modo satisfatório: "A Bahia é uma cidade, dia a dia, mais carente de hospitais" (...) incompletos, deficientes, lotados" (FALTA..., 1943, s/p). De fato, embora muitas instituições de saúde sejam inauguradas com toda pompa, com a presença dos seus pro-

29. Pedra fundamental - 1938 (VAI..., 1938). 
motores e de autoridades importantes como presidentes, ministros e prefeitos, o que se nota é que existe uma dificuldade em concluí-las, equipá-las e mantê-las em pleno funcionamento. Um dos problemas apontados é a falta crônica de recursos, que faz com que os administradores das instituições tenham que apelar continuamente para "o interesse" das autoridades (VISITA...1952, s/p) ou para as pessoas de "bom coração" (22 ANOS..., 1959) para poder concluir as obras e manter os edifícios em funcionamento.

A duração de determinadas obras demonstra a dificuldade para finalizar as construções dos edifícios. No caso do Hospital das Clínicas, a obra "marcha lentamente" (PAPEL..., 1948, s/p) e termina em 11 anos. Essa situação repete-se para os hospitais Aristides Maltez, Alfredo Magalhães, Martagão Gesteira, Ana Nery, etc.

A questão das limitações para equipar e manter os edifícios em funcionamento também é demonstrada:

Devemos ser francos. Aí estão, por exemplo, o Pronto Socorro e o Hospital Santa Terezinha. Edificações magníficas e instalações que se deve acreditar correspondem ao aspecto exterior. Entretanto, concluídos há já bastante tempo, ainda continuam inteiramente inúteis. Permanecem fechados. (...) De que valem hospitais luxuosos, suntuosos, magníficos para serem mostrados aos visitantes, se permanecem de portas cerradas, inteiramente inúteis? (INSTITUTO..., 1940, s/p). 
A situação específica dos edifícios para tratamento da "peste branca" é mencionada em outras circunstâncias. Afirma-se que a taxa de mortalidade se mantém alta na Bahia (MORAES, 1956, s/p), fato que é influenciado pela insuficiência do tratamento oferecido, já que "apenas 28\% dos hospitais, pavilhões e dispensários construídos pelo governo estão em funcionamento" (COLABORA..., 1947, $\mathrm{s} / \mathrm{p})$.

A condição das maternidades e hospitais infantis não é muito diferente, sendo a mortalidade de mães e dos seus filhos considerada bastante alta. Uma das dificuldades assinaladas é a carência de maternidades: "o número de leitos de que dispomos, nesta capital, é verdadeiramente irrisório face à população de gestantes" (LEITE, 1952, s/p). Menciona-se a carência de leitos principalmente para crianças pequenas e prematuras (OBRAS..., 1952).

A falta de hospitais na cidade causa a morte de pacientes "até na porta dos hospitais", (MORRE-SE, 1956.., s/p). Um repórter denuncia a complexidade do problema:

Atravessamos dias difíceis. (...) Há, entre tantos males, o da assistência médica que atinge sobretudo a camada grossa da população. Tratando-se de um povo dizimado por doenças do fígado e verminoses, tuberculose e a sífilis, seria de esperar que a população fosse condignamente amparada pelas autoridades, proporcionando facilidades hospitalares, remédios, o que de fato não acontece (MORRE-SE ..., 1956, s/p). 
As condições higiênicas dos edifícios são contestadas por algumas fontes, assim como as suas comodidades. É o que se pode notar em uma notícia que se refere ao Pronto Socorro, que possui "salas acanhadas. Gabinetes quase improvisados, inclusive o de Raios X. (...) Trancados os gabinetes, outros recintos, adaptados para os diversos misteres da ciência médica ainda por funcionar" (FREIRAS...,1942, $\mathrm{s} / \mathrm{p})$.

Além dos problemas de funcionamento, há uma má distribuição das instalações de saúde na cidade, com hospitais gerais concentrados em áreas centrais e poucos especializados dispostos em áreas distantes, de difícil acesso pela população. Segundo notícias, os bairros suburbanos "viveram sempre esquecidos pelos poderes públicos, relegados a um plano de inferioridade". Como exemplo, menciona-se o projeto da maternidade de Periperi, que nunca é concluído (DUTRA, 1948, s/p). Entre os hospitais realizados em áreas periféricas estão aqueles destinados a doenças infecciosas. Justificam-se suas localizações pela necessidade de estarem em áreas "vastas e aprazíveis" e, sobretudo, "salubres", mas nota-se que também se pretende manter os pacientes isolados do contato com o resto da população, por serem considerados uma "temerosa praga social" (ATRASADAS..., 1939, p.02).

Além de assinalar a situação precária dos hospitais, os documentos também mencionam a influência que as péssi- 
mas condições de moradias na cidade têm na saúde da população (HOSPITAL..., 1941, s/p): "Vivendo em situação difícil, habitando pardieiros ou choças que se amontoam em matagais infectos ou à beira de pântanos palúdicos, é sobretudo a família pobre que enfrenta (...) o problema da luta pela vida" (MAIS, 1944, s/p). Ressaltam-se também os contrastes dessa situação com o restante da cidade que possui "bangalôs elegantes, templos magníficos da cidade nova" (REDIMIR..., 1944: s/p).

Os rastros involuntários, tal como foram apresentados até aqui, revelam a existência de algumas instituições de saúde em Salvador que por algum motivo não ganham o mesmo destaque nos documentos do que as demais. As causas desse ocultamento merecem ser exploradas em posteriores pesquisas.

Tais rastros também assinalam que, apesar de muitas edificações serem realizadas segundo diretrizes técnicas e científicas que se manifestam nas soluções arquitetônicas, nem sempre, na prática, o resultado corresponde com as premissas iniciais. Apontam as limitações e contradições de um sistema de saúde que, apesar de prometer eficiência e racionalidade, é incapaz de atender de uma forma apropriada a maior parte da população soteropolitana, que permanece excluída dos padrões de modernidade difundidos pelos documentos. 


\section{Das pistas voluntárias aos restos involuntários}

Pouco resta da monumentalidade e imponência dos edifícios apontados inicialmente pelas pistas voluntárias. Também é difícil detectar a permanência das suas soluções eficientes e racionais. Há muito tais edifícios perderam suas condições moderníssimas para assumirem suas obsolescências permanentes, contrariando aquilo que se pretendia: que deixassem marcas persistentes dos seus impactos arquitetônicos ou das ações dos seus promotores para o melhoramento da saúde da população soteropolitana.

As pistas voluntárias também assinalam a intenção de validar todas as expressões arquitetônicas da modernidade de um modo permanente. Mas tal validação mostra-se extremamente precária e transitória. Na atualidade, as correntes arquitetônicas vigentes na modernidade não têm mais muita representatividade. Não existe um reconhecimento dos seus valores, nem por parte da população, das instituições, e nem mesmo pelos profissionais que atuam no meio arquitetônico. Essa situação pode ser demonstrada pelas inúmeras intervenções realizadas nos edifícios de saúde existentes na cidade no decorrer do tempo, ou mesmo pelas suas desativações ou demolições precoces.

Um dos pontos a ser assinalado é a descaracterização dos partidos adotados. Tais partidos são um elemento marcante na história hospitalar, referindo-se diretamente aos mé- 
todos para tratamento das doenças (MINISTÉRIO (1965); COSTA (2009)), que se transformam utilizando inicialmente um sistema de blocos múltiplos separados e posteriormente blocos independentes. Esses blocos podem ser compactos ou escalonados, com diferentes formatos, em "E", "H", "I", “L", etc. Atualmente, na maior parte dos edifícios tratados no texto, não se pode mais ter uma leitura clara do partido inicialmente adotado, uma vez que blocos secundários foram sendo anexados aos principais de modo indiscriminado. O mesmo pode ser dito dos monoblocos com formas prismáticas claras adotadas predominantemente pelo modernismo, que também perdem a clareza das suas leituras com a inserção de anexos ${ }^{30}$. Há também outros edifícios que foram completamente "soterrados" pelos seus anexos ${ }^{31}$.

Um dos aspectos mais marcantes dos edifícios que ado-

30. Essa situação acontece em maior ou menor medida em todos os hospitais que ainda existem. O IBIT passa por uma primeira ampliação realizada por Hélio Duarte e inaugurada em 12/05/1955. Embora o arquiteto transforme a volumetria anterior, o faz de acordo com as diretrizes anteriores, fato que não ocorre com alterações posteriores. Em 12/10/1971 inaugura-se o novo pavilhão do Hospital do Tórax, ao lado do IBIT, mas com um bloco modernista completamente independente, projetado pelo mesmo arquiteto (ANDRADE JÚNIOR (2011, p. 118); SILVEIRA (1977)). No caso do Hospital Espanhol realizamse vários anexos ao bloco eclético e um novo bloco modernista é construído em 1963 (NOVAS..., 1963, s/p).

31. Essa situação acontece no Pronto Socorro, atual Escola Estadual Manoel Novaes e no Hospital Português, por exemplo. 
tam soluções funcionalistas, mesmo naqueles que ainda são influenciados pelo art déco, é a presença nas fachadas de extensos terraços lineares que possibilitam a percepção de uma série de planos sobrepostos. Esses terraços são constantemente fechados para a ampliação das instalações hospitalares, impossibilitando a apreensão das linhas e planos característicos dos edifícios ${ }^{32}$.

Nos edifícios que utilizam soluções do modernismo também acontece uma interferência na percepção das suas volumetrias e na composição das suas fachadas, com aberturas ou fechamentos das suas partes constituintes, com a alteração dos elementos de vedação característicos como brises e cobogós, além do ocultamento da estrutura ${ }^{33}$.

Outro ponto que merece ser mencionado são os materiais utilizados interna e externamente, que são substituídos indiscriminadamente, sem preocupação de manutenção da unidade dos detalhes arquitetônicos característicos dos edifícios originais. As superfícies acabam se transformando em colchas de retalhos ${ }^{34}$. Ainda cabe destacar a presença

32. Essa situação acontece no Hospital das Clínicas, no Aristides Maltez e no Santa Terezinha. No antigo Preventório Santa Terezinha não existe mais referência a sua antiga fachada. Outros edifícios com características tendendo ao ecletismo ou ao art déco encontram-se mais preservados, como os pavilhões da Maternidade Climério Azevedo ou o Dispensário Ramiro Azevedo.

33. Isso se dá nos pavilhões modernistas no entorno do Hospital Santa Terezinha, na Clínica Tisiológica e no Hospital Martagão Gesteira. 
de outros elementos que interferem substancialmente na apreensão dos edifícios como a presença de aparelhos de ar-condicionado, grades, guaritas, cabos, toldos, painéis de propagandas... E, para completar, alguns edifícios sequer existem mais ${ }^{35}$.

Assim sendo, pode-se perceber que os traços das arquiteturas de saúde soteropolitanas ainda perduram, mas suas permanências estão sendo constantemente ameaçadas. Existe escassa preocupação por parte das instituições públicas ou privadas, dos profissionais de saúde ou mesmo dos arquitetos pela preservação das características fundamentais desses edifícios. Certamente a preservação das arquiteturas de saúde é um tema complexo, pois é necessária uma constante adaptação das suas instalações às técnicas hospitalares mais atuais. Mas trata-se de um desafio que é necessário afrontar para que tais arquiteturas possam continuar deixando seus rastros na cidade.

34. Essa situação acontece em praticamente todos os hospitais que ainda mantêm vestígios dos revestimentos originais misturados com aqueles de diferentes épocas.

35. Essa situação acontece com um dos blocos do Hospital Português, o mais antigo, substituído pelo edifício modernista da maternidade em 1957; o Hospital Alfredo Magalhães; a maior parte dos pavilhões do antigo hospital Juliano Moreira foi demolida. 


\section{Referências}

22 ANOS de lutas sem treguas. Boletim de divulgação da Liga Bahiana Contra o Câncer. Salvador, n. 2, ano 2, s/p, mai. 1959.

568 doentes mentais internados no Hospital Juliano Moreira. Diário de Notícias, Salvador, 27 ago. 1943. s/p.

AINDA no ambito de acção da Secretaria de Educação e Saúde. Diário de Notícias, Salvador, 10 nov. 1938, s/p.

ALBUM Comemorativo da Cidade do Salvador. São Paulo, Habitat Editôra, 1954.

AMARAL, Marivaldo. Da comadre para o doutor - a Maternidade Climério de Oliveira e a nova Medicina da Mulher na Bahia Republicana (1910-1927). 2005. 161f. Dissertação (Mestrado em História) - Universidade Federal da Bahia, Salvador.

ANDRADE JÚNIOR, Nivaldo. Arquitetura Moderna e as instituições de saúde na Bahia na década de 1930-1950. In: SOUZA, Christiane; BARRETO, Maria. (Org). História da Saúde na Bahia: instituições e patrimônio arquitetônico (1808-1958). São Paulo/Rio de Janeiro, Ed. Manole/Fiocruz, 2011. p. 101-145.

APOIO E auxílio para o prosseguimento da obra do IBIT. A presidente da LBA visita o edifício em construção. A Tarde, Salvador,11 mai. 1944. p.2.

APOIO oficial a uma obra grandiosa. Diário de Notícias, Salvador, 10 ago.1947. s/p.

ATRASADAS as obras do Santa Terezinha! A Tarde, Salvador, 10 fev. 1939. p.2.

BAHIA vai ter um hospital de cancerosos (A). [s.n], [s/i], 3 abr. 1951.s/p CAPITÃO Juracy Magalhães faz do seu relatório ao chefe da nação a sua mensagem à Assembléia Constituinte do Estado (O). Diário de Notícias, Salvador, 25 abr. $19352^{a}$ seção, s/p.

CARICCHIO, Enrani. Cia. Brasileira Imobiliária de Construções S.A., 
Bahia. Salvador, Imprensa Vitória, 1946.

CARICCHIO, Enrani. Cia. Brasileira Imobiliária de Construções S.A., Bahia. Salvador, Imprensa Vitória, 1949.

CASA das Mães (A). Diário de Notícias, Salvador, 08 ago. 1930. s/p. CEM contos para o Hospital Santa Izabel. Diário de Notícias, Salvador, 18 set. $1931 . \mathrm{s} / \mathrm{p}$.

CENTENÁRIO do engenheiro Oswaldo Augusto da Silva. A Tarde, Salvador, 5 ago. 1997.

CIA Construtora Nacional. Diário de Notícias, Salvador, 07 nov.1936. $\mathrm{s} / \mathrm{p}$.

CLíNICA Tisilógica da Universidade da Bahia. Revista Acrópole, Rio de Janeiro, n.223, p.254-255, mai. 1957.

COLABORA a Bahia na luta contra tuberculose. Diário de Notícias, Salvador, 18 dez.1947. s/p.

COMBATE decisivo à peste branca: novos hospitais serão inaugurados no dia 02 de julho. A Tarde, Salvador, 16 jun. 1952, p.02.

COMPANHIA Construtora Nacional S.A. Novo Pavilhão em construção na "Maternidade Climério de Oliveira". Diário de Notícias, Salvador, 25 abr. 1935, s/p.

CONSTRUCÇÃO de um modelar Hospital de Pronto Socorro (A). Diário de Notícias, Salvador, 22 fev.1935. s/p.

COSTA, Renato. Hospitais de clínicas de São Paulo, Salvador, Porto Alegre e Rio de Janeiro: arquitetura para a saúde entre duas modernidades. In: ENANPARQ, 2010, Rio de Janeiro. Anais..., Rio de Janeiro, Editora PROURB, 2010, s/p.

COSTA, Renato. Patrimônio moderno da saúde e os desafios para a sua valorização. O exemplo do Rio de Janeiro. In: VIII SEMINÁRIO DOCOMOMO BRASIL, 2009, Rio de Janeiro. Anais... Rio de Janeiro: Universidade Federal do Rio de Janeiro, 2009, s/p.

DISPENSARIO Ramiro de Azevedo - apella, pelo seu director, para os 
extremos da caridade particular (O).Diário de Notícias, Salvador, 09 abr. 1931. s/p

DUTRA, Luiz. Abandonados os suburbios da capital. Diário de Notícias, Salvador, 18 jul. 1948. s/p.

É UMA importante realização! Diário de Notícias, Salvador, 04 abr.1936. s/p.

EDIFÍCIO do Hospital. ETC, Salvador, ano VII, n.216, s/p, 15 jul. 1933.

EMILIO Odebrecht \& Cia. Construtores. Diário de Notícias, Salvador, 10 mar. 1938. s/p.

ENTRE o fechamento dos "Postos" e a abertura dos "Centros". Diário de Notícias, Salvador, 24 abr. 1931. s/p.

ENTREGA, ontem, do Edifício do IBIT. A solenidade de ontem - o auxílio de particulares e do Estado. Diário de Notícias, Salvador 24 abr. 1944. s/p.

FALTA de Hospitais na Bahia. Diário de Notícias, Salvador, 01 jul.1943. $\mathrm{s} / \mathrm{p}$.

FREIRAS enfermeiras, expontaneamente, velando pelos acidentados.

Diário de Notícias, Salvador, 16 jun.1942. s/p.

FUNDAÇÃO Anti-Tuberculosa Santa-Terezinha. Fundação Anti-Tuberculosa - Síntese das suas atividades. 1936-1945. Salvador: Imprensa Oficial, 1945. 15p.

GAGNEBIN, Jeanne Marie. Lembrar, esquecer, escrever. São Paulo: Editora 34, 2006, p.113.

GINZBURG, Carlo. Threads and traces: true, false, fictive. Los Angeles/Londres: University of California Press, 2012.

GRANDE obra para a ciência (Uma). A Tarde, Salvador, 17 out. 1952, p. 02.

HOCHMAN, Gilberto. Reformas, instituições e políticas de saúde no

Brasil (1930-1945) Educar em revista, Curitiba, p127-141, 2005. 
HOJE é o centenário de Aristides Maltez, um orgulho baiano na luta contra o câncer. Correio da Bahia, 31 ago. 1982. s/p

HOSPITAIS para os bancarios da Bahia. Diário de Notícias, Salvador, 30 nov. 1947. $s / p$

HOSPITAL Aristides Maltez - 40 anos de trabalho dedicados a Bahia. Gerência Hospitalar, Sociedade Beneficente São Camilo, Salvador, ano V, p.3, nov. 1992.

HOSPITAL Aristides Maltez e o controle do câncer do colo de útero no Brasil. Dynamis, Granada, vol.34, n. 1, 2014. Disponível em: <http:// dx.doi.org/10.4321/S0211-95362014000100003>. Acesso: 15/04/2016.

HOSPITAL das clínicas da Bahia, único no gênero em todo o Brasil. Diário de Notícias, Salvador, 23 mai. 1948, p.3.

HOSPITAL de crianças (O). Diário de Notícias, Salvador, 25. Jun.1932. $\mathrm{s} / \mathrm{p}$.

HOSPITAL Santa Terezinha vai ser, afinal, inaugurado (O). Diário de Notícias, Salvador, 22/05/1941, s/p.

IBIT cuida de construir um edifício para seus serviços e estudos. A Tarde, 21 mai. 1942. p.2

IMPORTANTE sessão no Hospital Santa Isabel. [s/n], 27/01/1940, s/p. INAUGURAÇÃO das novas instalações do H. do cancer. Diário de Notícias, Salvador, 22 mai. 1956. s/p.

INAUGURAÇÃO oficial do novo Hospital Português. Diário de Notícias, Salvador, 08 jun, 1931. s/p.

INAUGURADO o "Hospital Santa Terezinha" - obra de grande importancia social. Diário de Notícias, Salvador, 03/01/1942. s/p.

INSTITUTO DE PROTEÇÃO E ASSISTÊNCIA À INFÂNCIA DA BAHIA. Na inauguração do Primeiro Pavilhão do "Hospital Alfredo MagaIhães (para crianças). Salvador, INSTITUTO DE PROTEÇÃO E ASSISTÊNCIA À INFÂNCIA DA BAHIA, 1935.

INSTITUTO do câncer. A Tarde, Salvador, 26 out. 1940. s/p. 
JACOBINA, Ronaldo. A prática psiquiátrica na Bahia (1847-1947). 2001. 481f. Tese (Doutorado) - Fundação Oswaldo Cruz (FIOCRUZ-MS). Rio de Janeiro.

LEITE, A. Fraga. Maternidade popular a ser inaugurada ainda este mês.

Diário de Notícias, Salvador, 04 jan. 1952. s/p.

LINS, Eugenio; SANTANA, Mariely; SILVA, Marivaldo (org.). Salvador e a Baia de Todos os Santos. Sevilha: Junta de Andaluzia/Sevilha, 2012. $536 p$.

LIONS CLUBE DE SALVADOR. A nova cidade do Salvador. Porto Alegre: Artes Gráficas. S.A, 1968.

MACHADO, Almério. A história da pneumologia na Bahia: tributo ao professor César Augusto de Araújo. Gazeta Médica da Bahia Salvador, n.77, p.195-209, jul/dez. 2007. Disponível em: <www.gmbahia.ufba.br/ adm/arquivos/artigo14_20072.pdf>. Acesso em 16/04/2016.

MAIS de 2000 leitos para tuberculosos. Diário de Notícias, Salvador, 17 dez. 1947. s/p.

MAIS de mil internados já recebeu o Santa Terezinha. Diário de Notícias, Salvador, 12 abr. 1944. s/p.

MALTEZ, Ruy. Esboço histórico da Campanha Contra o Câncer na Bahia. Arquivos de Oncologia, Salvador, p.8-25, 1957.

MARGEM da construção do imponente palacio do Hospital das Clínicas - interessantes e opportunas referencias, derredor da grande e poderosa firma Emilio Odebrecht (Á). Diário de Notícias, Salvador, 21 out. 1937. s/p.

MINISTÉRIO DA SAÚDE. Departamento Nacional de Saúde. Divisão de Organização Hospitalar. História e evolução dos hospitais. Rio de Janeiro, 1965. 588p.

MODERNO Hospital para a Bahia - o sanatório Manoel Vitorino funcionará em 1949. A Tarde, Salvador, 18 set. 1947. p.2.

MORAES, Walfrido. Tuberculose: um doloroso problema social do país. 
Diário de Notícias, Salvador, 24 de jun. 1956. s/p.

MORRE-SE até na porta dos hospitais. Diário de Notícias, Salvador, 15 jun. 1956. s/p.

NÃO tardará a conclusão do Hospital Santa Terezinha - em menos de tres meses, entregal-o-ão prompto os constructores. Diário de Notícias, Salvador, 12 ago. 1938. s/p.

NOTÁVEL administração do Sr. Juracy Magalhães na Bahia. Correio de São Paulo, São Paulo, 25 jul. 1936. p.8.

NOVAS Instalações. Diário de Notícias, Salvador, 31 e 01 de abr. 1963. $\mathrm{s} / \mathrm{p}$.

O IBIT cuida de construir um edifício para seus serviços e estudos - o Estado auxiliará com $1 / 3$ do custo da obra - pormenores do futuro estabelecimento. A Tarde, Salvador, 21 mai. 1942. p.02

OBRA BENEMÉRITA da Santa Casa - a construcção do Ambulatório coube á Companhia Brazileira S/A. Diário de Notícias, Salvador, 21 fev. 1938. s/p.

OBRA DE finalidade humana. Diário de Notícias, Salvador, 26 mai. 1938. s/p.

OBRAS do Hospital das Crianças (As). Diário de Notícias, Salvador, 10 dez. 1952. p.3.

OLIVEIRA FILHO, Roque. Memórias Insanas (os hospitais psiquiátricos e a disciplinarização social em Salvador. 1994. 134f. Dissertação (mestrado na Faculdade de Filosofia e Ciências Humanas) - Universidade Federal da Bahia.

PAPEL de magna relavancia do $\mathrm{H}$. das Clinicas. Diário de Notícias, Salvador, 18 nov. 1948, p.3.

PORTO FILHO, Ubaldo. Alfredo Magalhães. Disponível em: <http:// www.ubaldomarquesportofilho.com.br/>. Acesso em: 16/04/2016.

PREVENTÓRIO de Brotas na berlinda (O). Diário de Notícias, Salvador, 29 abr.1936. s/p. 
PREVENTÓRIO na luta contra a tuberculose. Revista Rotary, Salvador, ano 1, n.1, p.24-28, jul. 1939.

PRIMEIRO passo está dado. A Tarde, Salvador, 14 abr. 1939. p.02.

PRÓ PRAVULUS - façamos um Hospital para as creanças. A Tarde, Salvador 18 out. 1935, p. 02.

PROTEÇÃO aos menores tuberculosos. Diário de Notícias, Salvador, 29 out.1948. s/p.

QUASE concluido o Instituto de Investigação da Tuberculose. Diário de Notícias, Salvador, 08 nov.1943. s/p.

QUE há de novo com o Hospital de Prompto Socorro e porque o mesmo ainda não está funcionando (O). Diário de Notícias, Salvador, 26 mai. 1938. s/p.

REAL Sociedade Portuguesa de Beneficência Dezesseis de Setembro e Hospital Português nos séculos XX e XXI. Disponível em: <http://150anos.hportugues.com.br/historia/plonearticle.2006-12-01.1518033679>.

Acesso em: 30/03/2016.

REDIMIR a infancia da mais cruel molestia. Diário de Notícias, Salvador, 06 jul.1944, s/p.

REVESTIR-SE-Á de grande solennidade - O lançamento, amanhã, da pedra fundamental do Hospital Das Clínicas. Diário de Notícias, Salvador, 18 out. 1937.

ROTARY CLUB DA BAHIA; GOVERNO DO ESTADO DA BAHIA. Polyanthéia. Salvador: Seção de Artes Graficas da Escola de Aprendizes de Bahia, 1937.

SAMPAIO, Lauro. Indicador e guia pratico da cidade do Salvador-Bahia. Salvador: Typographia Agostinho Barboza \& C. 1928.

SANTA Izabel comemora 100 anos. A Tarde, 31 jul. 1993.s/p.

SANTOS, André A. "Quem ampara a infância trabalha pela pátria": filantropia e puericultura no Instituto de Proteção e Assistência à Infância da Bahia (1903-1923). 2014. 196f. Dissertação (Mestrado em 
História). Universidade Estadual de Feira de Santana, Feira de Santana. SECRETARIA DE EDUCAÇÃO E SAÚDE. ESTADO DA BAHIA. Boletim de Educação e Saúde, Salvador, vol. 1, Bahia Gráfica e Editora Ltda, dez. 1940.

SERÁ instalado solenemente. Hoje às 15 horas, o Novo Serviço de Pronto Socorro. Diário de Notícias, Salvador, 18 set. 1941. s/p.

SILVA, Camila. Hospital do Instituto de Aposentadoria e Pensões dos Empregados em Transportes e Cargas: da Enfermagem Laica à Religiosa - 1946-1951. 2010. 182f. Dissertação (Mestrado em Enfermagem) - Universidade Federal do Rio de Janeiro, Rio de Janeiro.

SILVA, Maria Elisa. Registrar, orientar, controlar: o Dispensário Ramiro Azevedo e as ações contra a tuberculose na Bahia. In: XXVII SIMPÓSIO NACIONAL DE HISTÓRIA, 2013, Natal. Anais... São Paulo: Associação Nacional dos Professores e Universitários de História (ANPUH), 2013. Disponível: em: <http://www.snh2013.anpuh.org/resources/ anais/27/1371345582_ARQUIVO_COMUNICACAOXXVIIANPUH2013. Registrar,orientar,controlar.pdf>. Acesso em 17 mai. 2015.

SILVEIRA, José. A campanha antituberculosa na Bahia. Salvador: Companhia e Editora Gráfica da Bahia, 1937.

SILVEIRA, José. À sombra de uma sigla ou $\mathbf{4 0}$ anos de IBIT. Salvador, 1977.

SITUAÇÃO do Instituto de Proteção e Assistência à Infância da Bahia (A). A CAPITAL, Salvador, s/p, set. 1947.

SOCIEDADE Espanhola inaugura a 312 novos pavilhões com 182 leitos. Diário de Notícias, Salvador, 24 e 25, mar 1963. s/p.

SOUZA, Christiane. Hospital Ana Nery (1940-1950) - mais saúde para os trabalhadores da Bahia. In: XXVIII SIMPÓSIO NACIONAL DE HISTÓRIA, 2015, Florianópolis. Anais... Florianópolis, Associação Nacional dos Professores e Universitários de História (ANPUH), 2015. Disponível em: http://www.snh2015.anpuh.org/resources/anais/39/1434405665_ ARQUIVO_hospitalananeryanpuh2015.pdf>. Acesso em 17 mai. 2016. 
SOUZA, Christiane. Saúde Pública e Assistência na Bahia da primeira metade do século XX: o protagonismo dos médicos e das mulheres de elite. In: XXVI SIMPÓSIO NACIONAL DE HISTÓRIA, 2011, São Paulo. Anais... São Paulo: Associação Nacional dos Professores e Universitários de História (ANPUH), 2011. Disponível em: <http://www.snh2011. anpuh.org/resources/anais/14/1300886528_ARQUIVO_anpuh2011-historiasaudeBahia.pdf> Acesso em: 17 mai. 2016.

UM crédito especial de quase 15 milhões de cruzeiros. Diário de Notícias, Salvador, 19 dez. 1943. s/p.

UM RÓL de importantes construcções - está a cargo da grande firma Emilio Odebrecht. Diário de Notícias, Salvador, 23. Jun. 1938. s/p.

VAl começar a construção do Hospital Santa Luzia. Diário de Notícias, Salvador, 12 out. 1938. s/p.

VELOSO, Alberto. Na casa das criancinhas que a sorte esqueceu. Diário de Notícias, Salvador, 30 mar. 1946. s/p.

VISITA do Ministro da Saúde. A Tarde, 23 mai. 1956. s/p.

VISITA do prefeito ás obras do Hospital de Crianças, no Tororó. Diário de Notícias, Salvador, 30 dez. 1952, s/p. 
105 